\title{
Cue Validity and Object-Based Attention
}

\author{
Xun He, Silu Fan, Ke Zhou, and Lin Chen
}

\begin{abstract}
In a previous study, Egly, Driver, and Rafal (1994) observed both space- and object-based components of visual selective attention. However, the mechanisms underlying these two components and the relationship between them are not well understood. In the present research, with a similar paradigm, these issues were addressed by manipulating cue validity. Behavioral results indicated the presence of both space- and object-based components under high cue validity, similar to
\end{abstract}

\section{INTRODUCTION}

Space-based attention theories conceive of visual selective attention as a "spotlight" (Posner, 1980), "zoom lens" (Eriksen \& Yeh, 1985), or "gradient" (Downing \& Pinker, 1985), stating that attention selects a spatial region in the visual field and then highlights the processing of information within that region (for a review, see Cave \& Bichot, 1999). However, the context and structure of visual inputs may have an effect on attentional distribution. Accordingly, object-based attention theories propose that visual objects are the units for attentional selection. Based on Gestalt principles (Palmer, 1999; Wertheimer, 1938; Koffka, 1923), a visual object is organized preattentively, and is then selected by attention as a whole, "prior to its properties and independent of them" (Kahneman \& Henik, 1981; for a review, see Scholl, 2001). When a certain visual object is selected, the processing of all its attributes and parts will be facilitated uniformly, regardless of whether these features/parts are task relevant or not (Kahneman \& Henik, 1981).

Evidence for object-based attention has accumulated in recent years. In one pioneering study, Duncan (1984) used overlapping lines and boxes as objects, and found that when two task-relevant properties were located within the same object, the performance of reporting these properties was better than that when they were in different objects. In a recent study by Blaser, Pylyshyn, and Holcombe (2000), two superimposed circular striped Gabor patches were presented as objects, which changed smoothly along their feature dimensions, say,

Key Laboratory of Cognitive Science, Graduate School, Institute of Biophysics, Chinese Academy of Sciences the results of Egly et al.'s study. In addition, under low cue validity, the space-based component was absent, whereas the object-based component was maintained. Further eventrelated potential results demonstrated an object-based effect at a sensory level over the posterior areas of brain, and a spacebased effect over the anterior region. The present data suggest that the space- and object-based components reflect mainly voluntary and reflexive mechanisms, respectively.

saturation, and so forth. Observers could easily track multiple features of one of the two patches, suggesting an object-based selection. And, similar to Duncan's result, the performance of detecting a feature changing discontinuity was better when a single patch was attended than when performing the same task across two patches. Also using superimposed stimuli, Valdes-Sosa, Bobes, Rodriguez, \& Pinilla (1998) investigated the neural correlates of object-based attention with the event-related potential (ERP) technique. Their results indicated that larger posterior $\mathrm{P} 1$ and $\mathrm{N} 1$ components of the motion-onset ERPs were associated with the attended set of rotating dots (object) compared to the unattended set (object). Furthermore, a functional magnetic resonance imaging (fMRI) study by O'Craven, Downing, and Kanwisher (1999) revealed that directing attention to one attribute of an object would produce not only enhancement of activation in the cortical region coding that attribute, but also enhancement of activation in the area for another, irrelevant attribute of the same object.

Whereas all the above-documented studies provided strong support for object-based selection, the present experiments are based on another classic work by Egly, Driver, and Rafal (1994). In their study, the objects were two parallel rectangles, with the distance between the cued location and other two critical locations kept identical. Subjects were instructed to detect a luminance increment at one end of a rectangle immediately after the peripheral cue. Within the cued object, invalid targets had longer reaction times (RTs) than the valid ones, showing a pure spatial attentional cost. This was interpreted as a space-based component. They also found a significant object-based component, that is, an additional RT cost for invalid targets located in the 
uncued object compared with invalid targets in the cued object, suggesting the attentional selection of objects.

Much remains unclear, however, about the mechanisms underlying the space- and object-based components, and the relationship between them. For example, do these components share a common attentional selection mechanism? Given that an informative peripheral cue was used in the study of Egly et al. (1994), it is unclear which component reflects the effect of the predictive information, and which is related to the physical properties of the cue. Previous studies suggested that peripheral cues trigger both reflexive and voluntary orienting mechanisms. The reflexive mechanism is triggered by the immediate physical properties of the cue and is little affected by cue validity. The voluntary mechanism, however, requires spatial expectancy on the basis of cue validity (Müller \& Findlay, 1988; Müller \& Rabbitt, 1989; see also Berger, Dori, \& Henik, 1999). In the study of Egly et al. (1994), visual attention was covertly oriented by spatially informative peripheral cues along with "space-based" instructions, predicting the most probable location of target onset. Therefore, a plausible answer to these questions is that the voluntary and reflexive mechanisms are closely related to the space- and object-based components, respectively.

This proposal was tested by the present experiments, which used a similar paradigm to that of Egly et al. (1994). The validity of the spatial peripheral cue was manipulated. Because cue validity affects the voluntary mechanism but not the reflexive one (Müller \& Rabbitt, 1989; Müller \& Findlay, 1988), the proposed hypothesis predicts that the space-based component should vary with cue validity. Specifically, when the validity of a predictive cue is not high enough, the space-based component of RT results may be absent, because the prediction of a certain location is not powerful enough to produce observable spatial RT cost. The object-based component, however, will maintain its presence under different levels of cue validity.

The above hypothesis, specifically the proposal regarding the reflexive mechanism, was further validated with the ERP technique, which is particularly useful for determining the stage at which an effect takes place (see Luck \& Hillyard, 2000; Rugg \& Coles, 1995). A wealth of electrophysiological studies have shown that visual attention enhances early sensory ERP components, such as P1, N1, or both, which are thought to be early indices of selection (e.g., Heinze et al., 1994; Eimer, 1993; Luck, Fan, \& Hillyard, 1993; Heinze, Luck, Mangun, \& Hillyard, 1990; Mangun \& Hillyard, 1990, 1991; Eason, 1981; for recent reviews, see Luck \& Hillyard, 2000; Eimer, 1998; Luck, 1998; Mangun, 1995). In particular, Hopfinger and Mangun (1998, 2001) recently provided converging evidence that reflexive attention transiently facilitates sensory process- ing of visual inputs (see also Mangun, Jha, Hopfinger, \& Handy, 2000). In their studies, a nonpredictive peripheral cue, which triggers the reflexive attention mechanism, preceded each target stimulus. In both form discrimination (Hopfinger \& Mangun, 1998) and luminance detection (Hopfinger \& Mangun, 2001) tasks, an enhanced sensory ERP component (P1) was associated with the cued target stimuli. They concluded that reflexive attention modulates early sensory processing at the same stage as does voluntary attention. In accordance with their observations, in the present study an enhancement of sensory ERP component(s) is expected for the targets that are located within the cued rectangle. Because our hypothesis suggests that reflexive attention selects objects rather than spatial locations, all targets within the cued object should have similar ERP modulations on the same sensory component(s).

The present study addressed the issue of voluntary/ reflexive mechanisms with three experiments. Experiment 1 and Experiment 2 obtained behavioral data under high and low cue validity, respectively, and under low validity conditions, Experiment 3 used the ERP technique to investigate the electrophysiological correlates of attention. There were three cue-target relation types. The cue and the target were presented at the same location (valid) or at different locations (invalid). For invalid locations, the target could be in the cued object or in the uncued object. These three conditions were termed valid, intra, and inter conditions in the present article, respectively. Furthermore, three patterns of results were considered in the present article, based on the idea of space- and object-based attentional selection. When the valid condition was different from both invalid conditions and the two invalid conditions did not differ from one another, the term spatial pattern was used, reflecting the space-based selection only. When the valid and intra conditions did not differ from one another while both of them differed from the inter condition, this was termed an object pattern, demonstrating the object-based selection only. And if both space- and object-based components were observed, as in the study of Egly et al. (1994), it was termed a mixed pattern.

\section{RESULTS}

\section{Behavior}

Figures 1 and 2 and Table 1 present the behavioral results. Under the high cue validity (Experiment 1), repeated measures analysis of variance (rm-ANOVA) showed a significant main effect of the factor of cuetarget relation, $F(2,22)=19.54, p<.0001$. Further pairwise comparisons indicated that the RTs of the three conditions corresponded with the mixed pattern, replicating the results of Egly et al. (1994). The valid condi- 


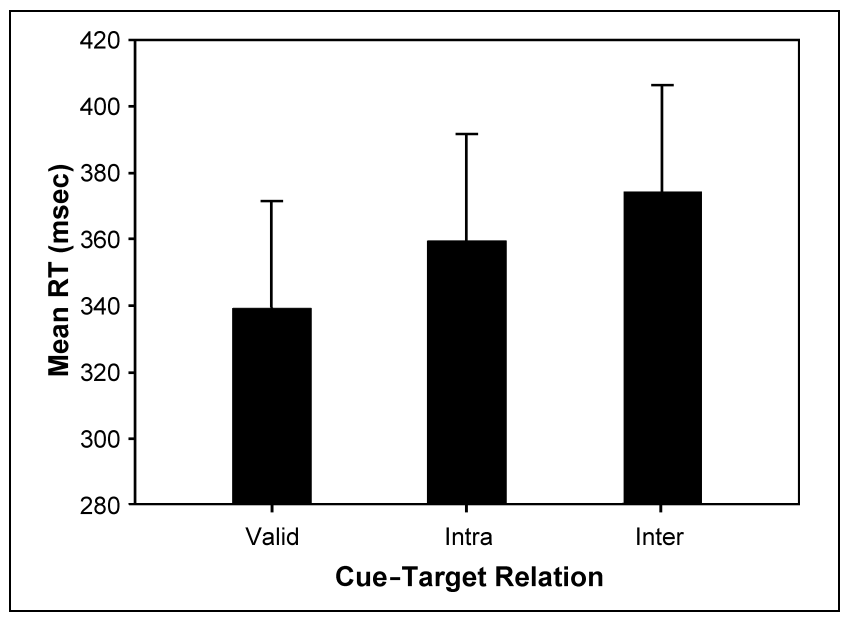

Figure 1. RT result of Experiment 1 (standard errors indicated). The valid has a shorter RT than the intra, and the intra has a shorter RT than the inter, showing the mixed pattern.

tion had a significantly shorter RT than the invalid conditions (the intra and the inter), and the intra was responded to significantly faster than the inter. The mean RTs were 339 (valid), 359 (intra), and $374 \mathrm{msec}$ (inter), respectively. The mean miss rate of responses was $0.2 \%$ and mean false alarm rate was $3.7 \%$.

In contrast, experiments with low cue validity (Experiments 2 and 3) produced different results. In Experiment 2, rm-ANOVA showed a significant main effect of cue-target relation, $F(2,22)=13.35, p<.0003$. Further pairwise tests for cue-target relation factor demonstrated the object pattern: Both the valid and intra conditions had significantly shorter RTs than the inter, and the valid and intra conditions did not significantly differ from one another. The mean RTs were 328 (valid), 331 (intra), and $353 \mathrm{msec}$ (inter). Subjects missed keystrokes by an

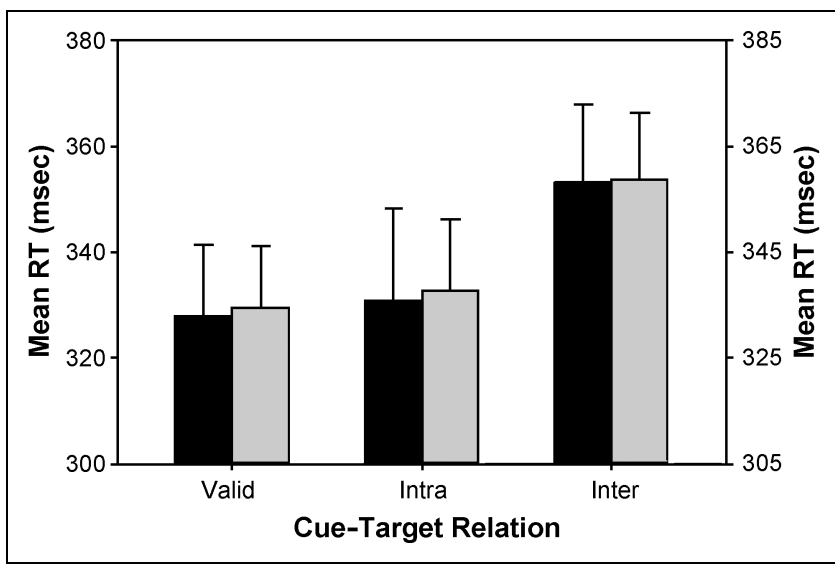

Figure 2. RT results of Experiments 2 (black bars) and 3 (gray bars) (standard errors indicated). The valid and the intra do not differ from one another, and both have shorter RTs than the inter, demonstrating the object pattern.
Table 1. The Main Effect and Pairwise Comparisons of RTs

\begin{tabular}{|c|c|c|c|c|c|}
\hline & \multicolumn{2}{|c|}{ Main Effect } & \multicolumn{3}{|c|}{ Pairwise Comparisons $(p)$} \\
\hline & $F$ & $p$ & $\begin{array}{l}\text { Valid: } \\
\text { Intra }\end{array}$ & $\begin{array}{l}\text { Valid: } \\
\text { Inter }\end{array}$ & $\begin{array}{l}\text { Intra: } \\
\text { Inter }\end{array}$ \\
\hline Experiment 1 & 19.54 & $<.0001$ & $<.008$ & $<.0002$ & $<.009$ \\
\hline Experiment 2 & 13.35 & $<.0003$ & $>.6$ & $<.0008$ & $<.0004$ \\
\hline Experiment 3 & 62.21 & $<.0001$ & $>.2$ & $<.0001$ & $<.0001$ \\
\hline
\end{tabular}

error rate of $0.1 \%$ and had a false alarm rate of $4.5 \%$ on average.

Experiment 3 replicated the results of Experiment 2 . A significant main effect of cue-target relation was found, $F(2,38)=62.21, p<.0001$. The mean RTs were 334 (valid), 338 (intra), and $359 \mathrm{msec}$ (inter), showing the object pattern. Subjects had a mean miss rate of $0.4 \%$ and a mean false alarm rate of $5.2 \%$.

In all three experiments, the main effects of background layout $(F \mathrm{~s}<.90, p \mathrm{~s}>.3)$ and its interactions with cue-target relation ( $F \mathrm{~s}<2.42$, ps $>.1$ ) did not approach statistical significance.

\section{Electrophysiology}

The ERP waveforms of the valid, intra, and inter conditions were averaged across subjects and are plotted in Figure 3. A temporal-occipital P1 was observed but was small in amplitude. Other deflections were clearly identified: anterior N1 (central), posterior N1 (temporaloccipital), P2 (frontal), and a widespread late positive deflection (LPD; distributed over parietal, central-parietal, and lateral central to frontal areas). These five components were analyzed with mean amplitude calculations and rm-ANOVAs. Time windows for calculation, applied sites, and mean amplitudes are shown in Table 2 . Statistical results are presented in Table 3.

The P1 component did not show any effect of cuetarget relation at any of the three electrode pairs $(F \mathrm{~S}<$ $1.34, p s>.2)$ or any hemispheric difference $(F s<3.44$, ps $>$.079). No interaction between these two factors was found $(F \mathrm{~s}<.77$, ps $>.4$ ).

Figures 4 and 5 display the distribution and statistical results of the anterior and posterior N1s. For the anterior N1, main effects of cue-target relation were observed on all eight measured sites ( $F$ s $>8.84$, ps $<.0009)$. Further tests showed the spatial pattern in which the valid condition had a significantly larger amplitude than the intra and the inter. No significant effect of hemisphere was observed on the lateral sites $(F \mathrm{~s}<3.83$, ps $>.065)$. A significant interaction between cue-target relation and hemisphere was found only at $\mathrm{C} 3 / 4, F(2,38)=5.85, p<.011$; other sites: $F \mathrm{~s}<.92$, $p s>$.4. However, further tests indicated that both sites $\mathrm{C} 3$ and $\mathrm{C} 4$ yielded the spatial pattern (valid vs. intra: 


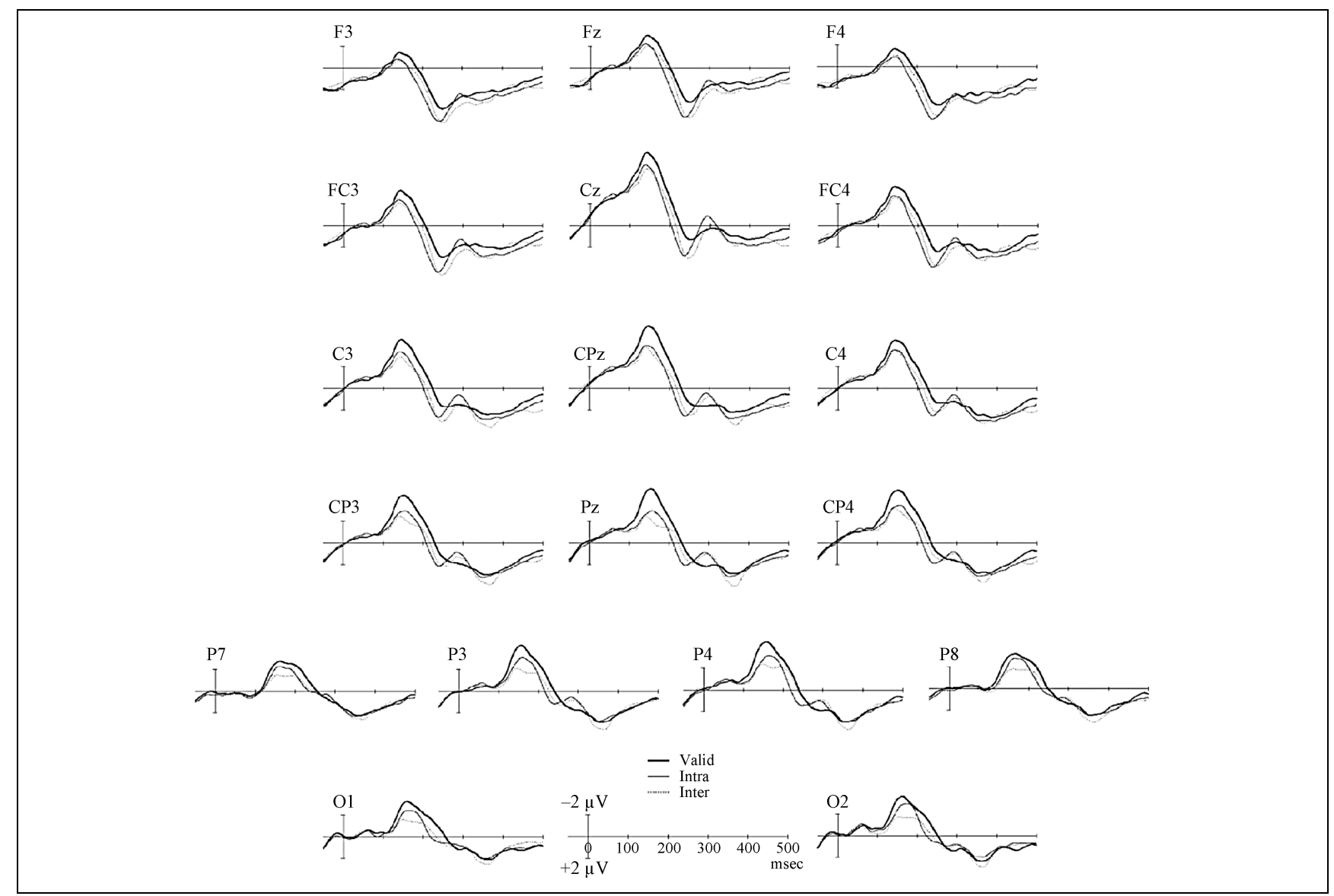

Figure 3. Grand average ERPs (averaged over all four target positions) in Experiment 3.

$p s<.016$, valid vs. inter: $p s<.004$, intra vs. inter: ps $>.057)$.

For the posterior N1, the main effects of cue-target relation were also obtained at the six measured sites ( Fs $>11.51, p s<.0004)$. At the lateral parietal sites (P3/4), results followed the mixed pattern: The valid had a significantly larger amplitude than the intra, and the intra had a significantly larger amplitude than the inter. For lateral occipital (O1/2) and temporal (P7/8) sites, however, the object pattern was obtained, with the valid and the intra amplitudes being significantly larger than the inter. No significant main effect of hemisphere $(F \mathrm{~s}<$ $3.08, p s>.095)$ or interaction $(F \mathrm{~s}<.90, p \mathrm{~s}>.3)$ was observed.

Attention effects were also obtained on the later components (P2 and LPD; see Figure 6). The P2 amplitudes yielded significant main effects of cue-target relation $(F \mathrm{~s}>11.49, p s<.0003)$ and showed the spatial pattern in which the valid targets elicited significantly smaller amplitudes than either the intra or the inter. The LPD data showed the main effects of cue-target relation at $\mathrm{CP} 3 / 4, \mathrm{CPz}$, and $\mathrm{Pz}(F \mathrm{~s}>4.02$, ps < .037). Among these sites, $\mathrm{CP} 3 / 4$ and $\mathrm{Pz}$ showed the object pattern in which the inter was significantly smaller than the valid and the intra. No significant effect of hemisphere $(F \mathrm{~s}<$
2.57 , $p \mathrm{~s}>.1$ ) or interaction $(F \mathrm{~s}<2.38$, $p \mathrm{~s}>.1$ ) was observed on these two components.

\section{DISCUSSION}

Space- and object-based attention theories diverge as to what is the fundamental unit of attentional selection. Because attention facilitates processing of the selected stimuli, these two schools of theories can be distinguished from each other by their different predicted response patterns. In particular, when a peripheral flash captures attention, the space-based theories predict enhanced processing of the stimulus at that spatial location, whereas the object-based theories propose facilitated responses for the cued perceptual object. Previously, in a spatial cueing paradigm with an informative peripheral cue, both space- and object-based components were found, showing the mixed pattern (Egly et al., 1994). This indicated the presence of both space- and object-based selections in a single task. The present study aimed at unraveling these two components by manipulating cue validity. Because voluntary attention is based on expectancy, whereas reflexive attention is little affected by cue validity (Müller \& 
Table 2. Mean ERP Amplitude Analyses in Experiment 3

\begin{tabular}{|c|c|c|c|c|c|}
\hline \multirow[b]{2}{*}{ Peak } & \multirow[b]{2}{*}{ Window (msec) } & \multirow[b]{2}{*}{ Electrode(s) } & \multicolumn{3}{|c|}{ Amplitude $\pm S E(\mu V)$} \\
\hline & & & Valid & Intra & Inter \\
\hline & & $\mathrm{P} 3 / 4$ & $-0.62 \pm .51$ & $-0.46 \pm .44$ & $-0.41 \pm .53$ \\
\hline & & $\mathrm{O} 1 / 2$ & $-0.48 \pm .36$ & $-0.26 \pm .32$ & $-0.11 \pm .34$ \\
\hline & & $\mathrm{C} 3 / 4$ & $-4.25 \pm .64$ & $-3.33 \pm .61$ & $-3.06 \pm .63$ \\
\hline & & $\mathrm{Cz}$ & $-6.46 \pm .66$ & $-5.41 \pm .73$ & $-5.00 \pm .76$ \\
\hline & & $\mathrm{CP} 3 / 4$ & $-4.30 \pm .73$ & $-2.96 \pm .69$ & $-2.65 \pm .70$ \\
\hline & & $\mathrm{O} 1 / 2$ & $-3.20 \pm .55$ & $-2.56 \pm .75$ & $-1.53 \pm .67$ \\
\hline \multirow[t]{3}{*}{$\mathrm{P} 2$} & $230-260$ & $\mathrm{~F} 3 / 4$ & $3.47 \pm .46$ & $4.63 \pm .42$ & $4.53 \pm .40$ \\
\hline & & $\mathrm{Fz}$ & $2.96 \pm .47$ & $4.14 \pm .48$ & $4.35 \pm .48$ \\
\hline & & $\mathrm{FC} 3 / 4$ & $2.45 \pm .44$ & $3.69 \pm .45$ & $3.91 \pm .46$ \\
\hline \multirow[t]{3}{*}{ LPD } & $350-380$ & $\mathrm{CP} 3 / 4$ & $2.80 \pm .49$ & $2.99 \pm .59$ & $3.56 \pm .70$ \\
\hline & & $\mathrm{CPz}$ & $2.16 \pm .50$ & $2.70 \pm .64$ & $3.17 \pm .83$ \\
\hline & & $\mathrm{P} 3 / 4$ & $2.84 \pm .44$ & $2.70 \pm .56$ & $3.40 \pm .71$ \\
\hline
\end{tabular}

Measurement windows $(\mathrm{msec})$, electrodes, and results $(\mu \mathrm{V})$ of the mean amplitude calculation are shown for each component. The anterior and posterior N1s are abbreviated as N1ant and N1post, respectively. LPD signifies the late positive deflection.

Rabbitt, 1989; Müller \& Findlay, 1988), this validity manipulation is believed to modify the component related to voluntary selection, but not the one related to reflexive selection.

In the present study, Experiments 1 and 2 yielded different RT results, showing that the space-based component varied with cue validity. Under conditions of high validity, the behavioral responses demonstrated the mixed pattern. However, when cue validity was low, the object pattern was shown. In other words, the space-based component was evident when the cue validity was high, and subsided when the validity fell. In contrast, under both the high- and low-validity conditions, the object-based component was evident. These results demonstrate that the space-based component was affected by cue validity, whereas the object-based one was not. Note that in the present experiments, instructions were "space based," providing subjects with the information of most probable target onset location. It seems that the voluntary mechanism, which is guided by the spatial information, does not select objects. Accordingly, it is suggested that the space- and object-based components mainly reflect the voluntary and reflexive attention mechanisms, respectively.
We investigated the underlying neural substrates of these behavioral effects in Experiment 3. Of particular interest was whether we could identify an object-based electrophysiological activation associated with the reflexive selection based on visual objects. As noted in the Introduction, Hopfinger and Mangun (2001) provided evidence that the reflexive mechanism induces enhancement of an early sensory ERP component in a simple luminance detection task with a requirement of speeded responses (see also Luck \& Hillyard, 2000). Therefore, according to our proposal that reflexive attention selects objects in the present paradigm, an enhancement of sensory-level responses such as P1, N1, or both would be expected for stimuli within the selected object.

Analyses of the sensory-level components confirmed this prediction. At temporal-occipital electrodes, targets in the cued object elicited a larger posterior N1, showing the object pattern and paralleling the RT results. This result suggests that when a peripheral cue directs attention, the reflexive mechanism selects the visual objects at an early sensory processing stage. This is the first evidence that visual objects can be selected at an early stage under the control of voluntary spatial attention (for evidence of early voluntary object selection, 
Table 3. Main Effects of Cue-Target Relation and Results of Further Pairwise Comparisons of ERP Amplitudes in Experiment 3

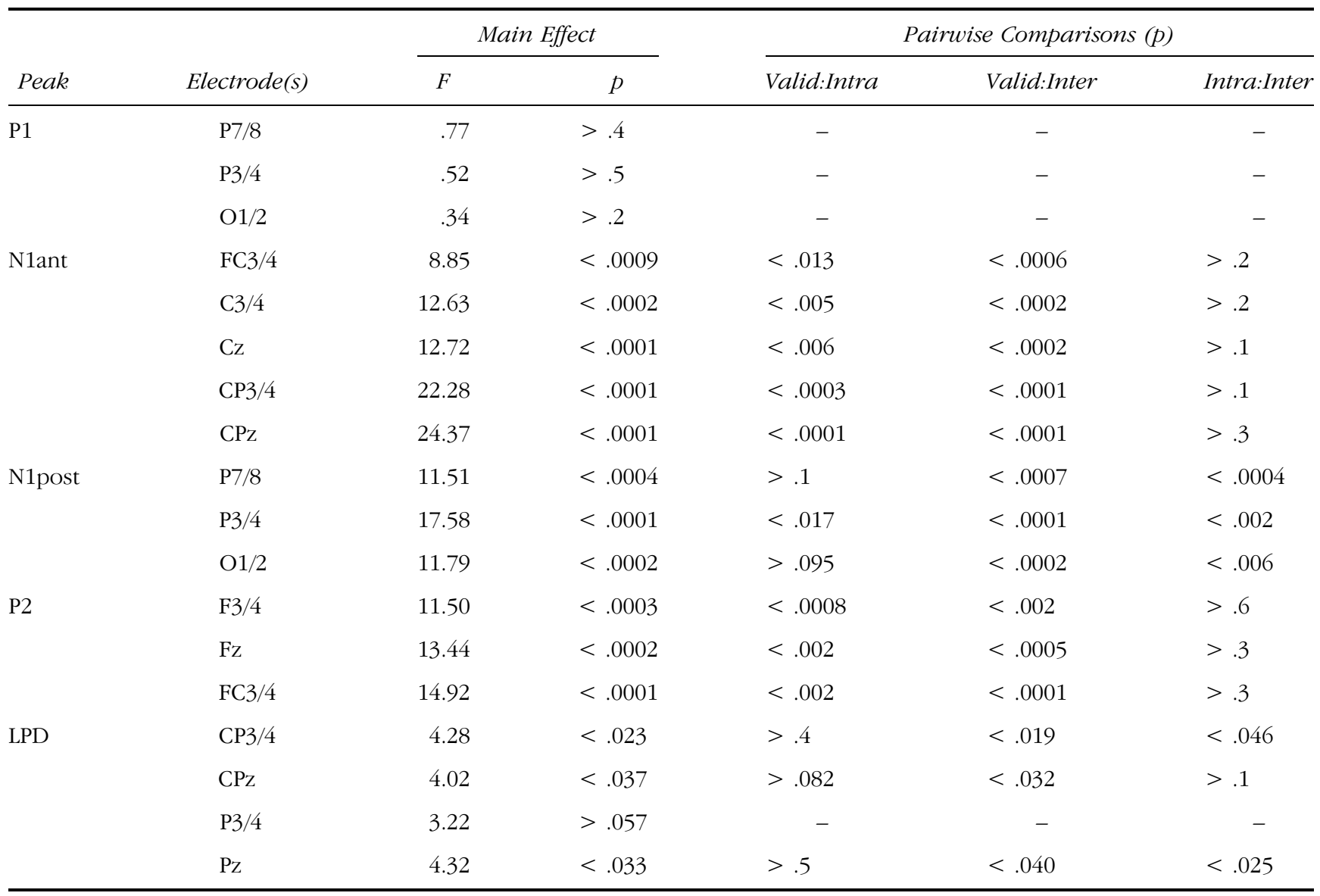

Abbreviations as in Table 2 .

see, e.g., Valdes-Sosa et al., 1998). In the present study, no attention effect was found in the time range of the P1 component. This differs from the results of Hopfinger and Mangun's study (2001), in which P1 enhancement was observed in a simple detection task. This distinction may be due to a variety of differences between the two studies. For instance, we used an onset flash as peripheral cue, whereas they used offset to trigger the attentional orienting. Furthermore, we used a fixed and longer cue-target onset asynchrony (CTOA) (300 msec) compared with their jittered and much shorter CTOAs (68-268 msec). Nonetheless, the present ERP results suggest that visual objects are selected by reflexive attention at an early sensory level. Because previous studies suggested that the posterior N1 is generated in extrastriate visual cortex and can be accounted for by the same or neighboring dipolar source(s) as that of the P1 component (Di Russo, Martínez, Sereno, Pitzalis, \& Hillyard, 2001; Martínez et al., 2001; Clark \& Hillyard, 1996; Clark, Fan, \& Hillyard, 1995; Gomez Gonzalez, Clark, Fan, Luck, \& Hillyard, 1994), the present data indicate that reflexive attention can modulate early neural processing in the extrastriate cortex. This suggestion is consistent with the results of Hopfinger and Mangun
Figure 4. Topographic voltage maps of grand average ERPs (averaged over all four positions) from 120 to 196 msec after target onset. The anterior N1 was very large and centrally distributed. The posterior N1 was much smaller and had a temporal-occipital distribution. The data shown are from the intra condition.

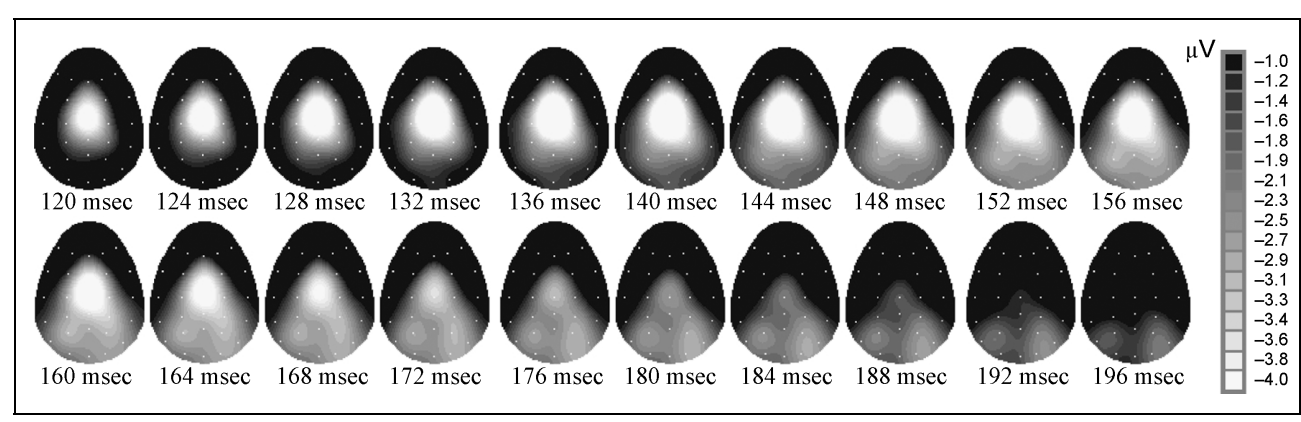




\section{A}
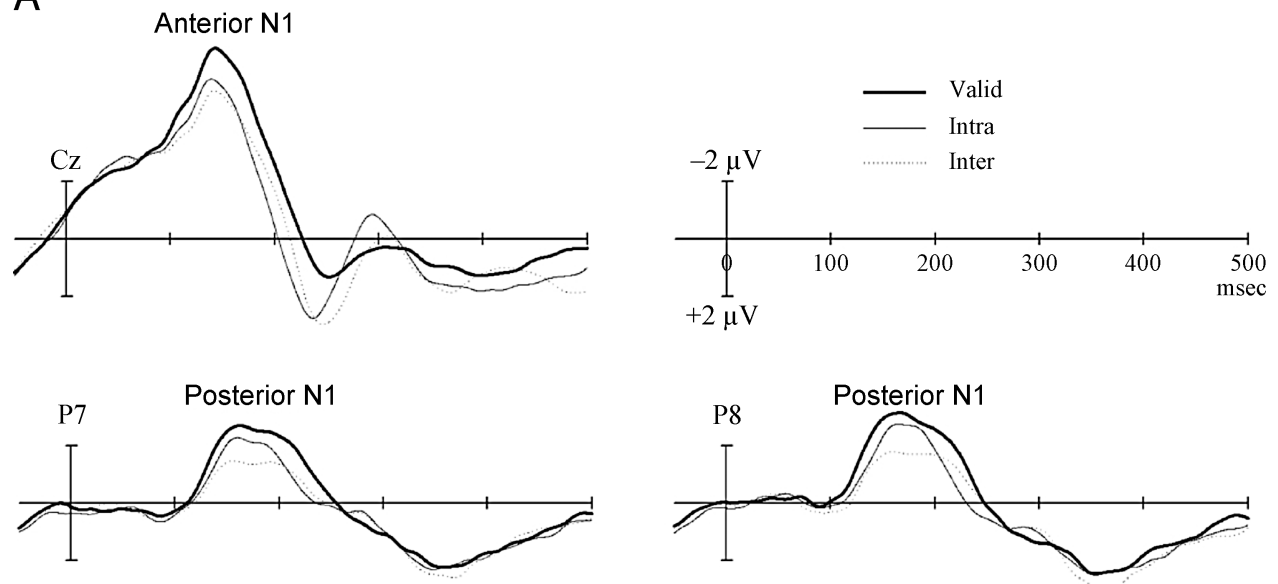

B
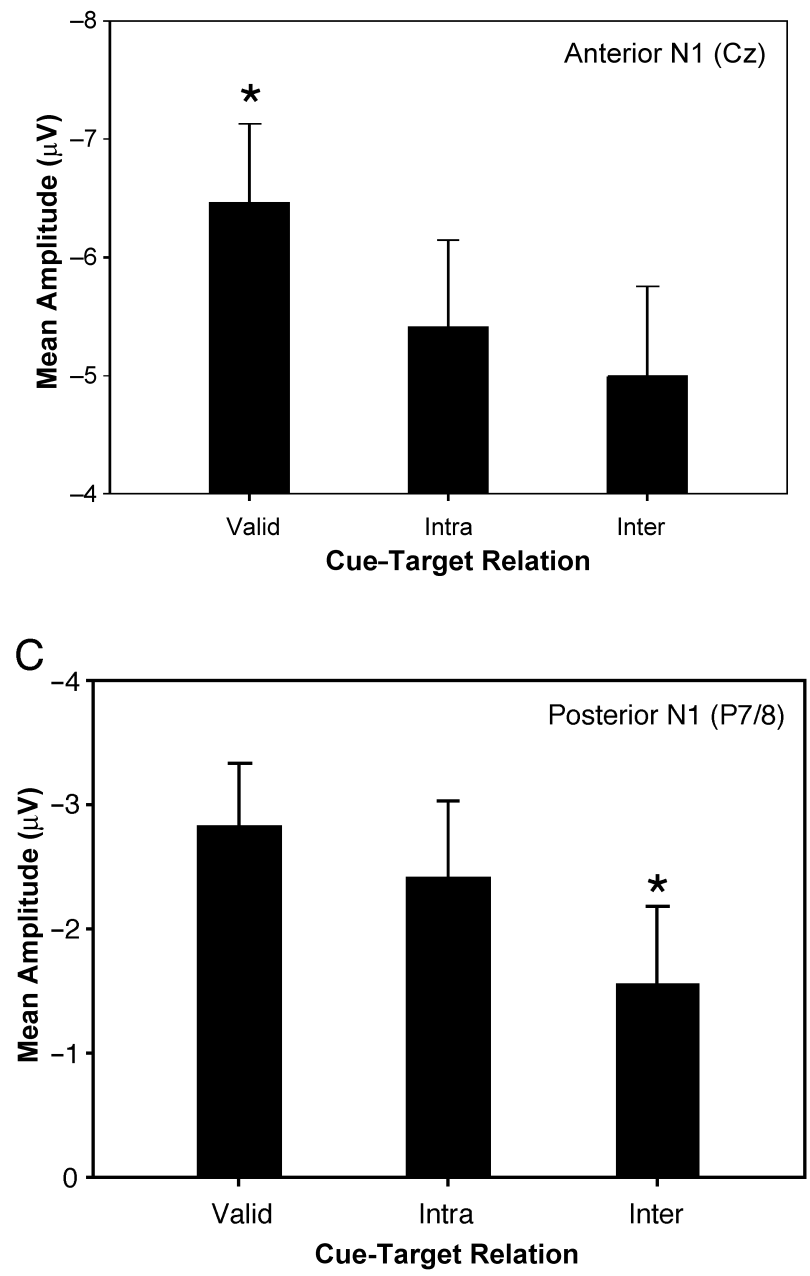

Figure 5. ERP results of the anterior and posterior N1s in Experiment 3. (A) Target-elicited ERP waveforms at Cz (anterior) and P7/8 (posterior). ERPs were averaged over all four target positions. (B) Result of anterior N1 amplitude (Cz). Difference of mean amplitude is significant at sites FC3/4, C3/4, Cz, CP3/4, and CPz. All these sites yield the spatial pattern. (C) Result of posterior N1 amplitude (P7/8). Difference of mean amplitude is significant at sites $\mathrm{P} 3 / 4, \mathrm{P} 7 / 8$, and O1/2. Activities at P7/8 and O1/2 show the object pattern. In (B) and (C), the asterisk-marked bar has a different amplitude compared to the other two conditions, and the other two conditions do not differ from one another.

(1998, 2001). Therefore, the RT and ERP results provide converging evidence for the reflexive object-based selection proposal.
Another interesting result comes from the anterior N1. Although no space-based component was observed in the RT results, there was a significant spatial effect on 


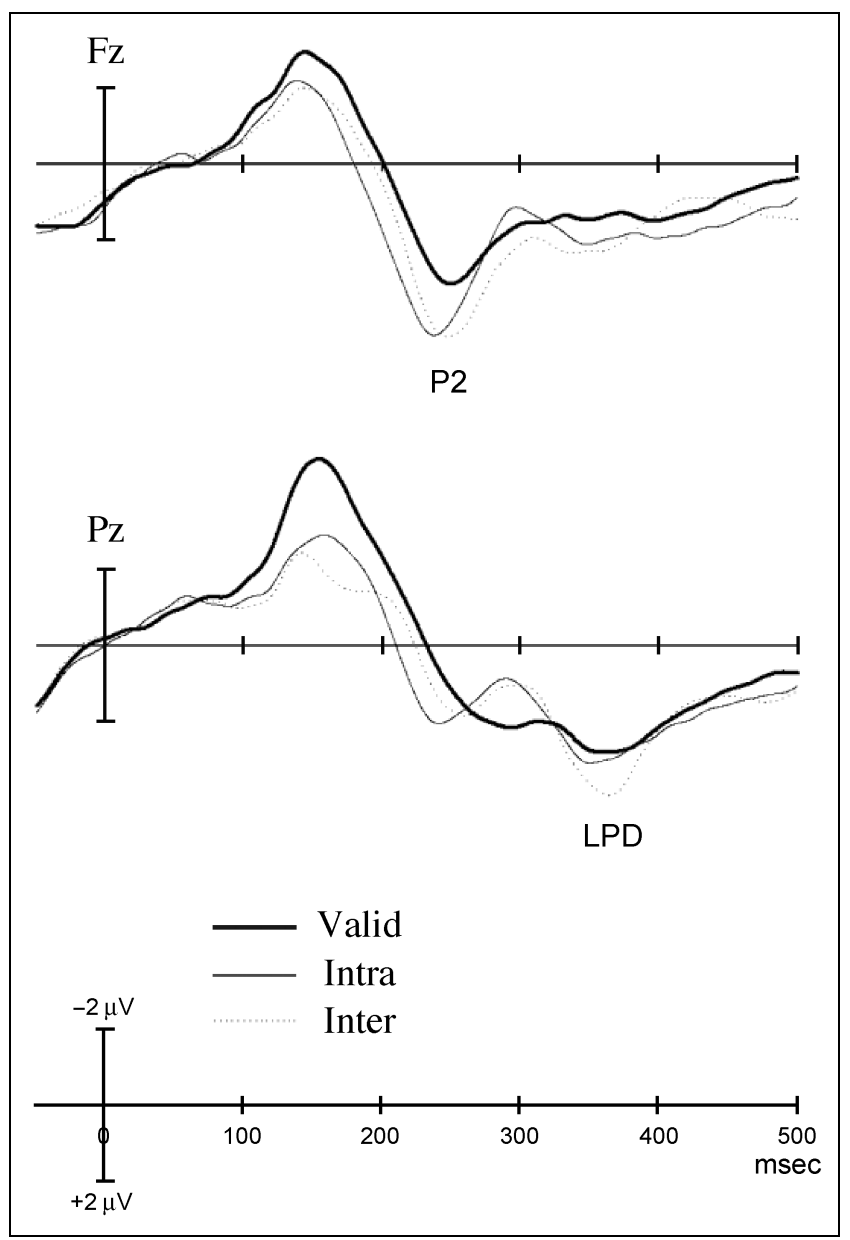

Figure 6. Grand average ERP waveforms (4-position-collapsed) at electrodes Fz and Pz, showing the P2 component and the LPD.

the anterior N1 from the frontal-central to the centralparietal areas. This may indicate the participation of spatial voluntary attention. Note that the validity of the peripheral cue in the ERP experiment was $58 \%$, which is well above chance level and hence informative. Besides the predictive value of the cue, the instructions given to subjects also promoted space-based selection. Therefore, it seems that the spatial voluntary attention still played a role even when the cue validity was relatively low, even though the RTs did not reveal such a spatial voluntary component. Previous ERP studies have found that spatial voluntary attention can yield larger anterior N1 for targets located within the selected region of space (e.g., Clark \& Hillyard, 1996; Gomez Gonzalez et al., 1994; Luck et al., 1993; Mangun \& Hillyard, 1990, 1991). The present data are consistent with these previous results, suggesting that the spatial pattern on the anterior N1 reflects, at least in part, the spatial voluntary mechanism in the informative cueing paradigm.

Taking the results of the anterior and posterior N1s together, both space- and object-based attentional selections were reflected in the ERP responses, suggesting that at the sensory level, both spatial and object- based attentional selections take place. The anterior N1 showed the spatial pattern and reflected neural activity underlying the voluntary control of spatial attention. In contrast, the posterior N1 exhibited the object pattern and reflected neural correlates related to object-based reflexive selection. The dissociation between the activity patterns of the anterior and posterior N1s seems to provide a clue about the differentiation of the voluntary and reflexive attentional processing, and calls for further investigations.

After the sensory processing stage, the P2 amplitude changes showed the spatial pattern, whereas the object pattern was observed in the LPD. These data suggest that the voluntary and reflexive mechanisms can affect the information processing at multiple stages. At the temporal stage of the LPD, the processing of visual objects was in the late period, and a reaction decision had already been made. Therefore, the neural activity manifested by the LPD may partly reflect the decisionmaking process in which the object-based selection dominated.

Hopfinger and Mangun (1998, 2001) proposed that the reflexive attention effects on the P1 and P300 components in their studies can be attributed to automatic processes, since the same enhancements occur in both simple detection (Hopfinger \& Mangun, 2001) and complex discrimination (Hopfinger \& Mangun, 1998) tasks. In general, there is a consensus that reflexive attention operates in an automatic manner (see, e.g., Pashler, Johnston, \& Ruthruff, 2001; Müller \& Rabbitt, 1989; Müller \& Findlay, 1988; Jonides, 1981). However, in the strict sense of automaticity (in other words, strong automaticity), that is, meeting the criteria of being insensitive to perceptual load and being not subject to voluntary control (Yantis \& Jonides, 1990; Shiffrin \& Schneider, 1977), there is disagreement as to whether reflexive orienting can always be considered an automatic process (see, e.g., Pashler et al., 2001; Yantis, 1998; Yantis \& Jonides, 1990). Therefore, whether the reflexive attention engaged in the present study selects objects automatically is still an open question that deserves further study.

\section{METHODS}

\section{Participants}

The number of accepted volunteers was 12 (6 women), 12 (6 women), and 20 (8 women) for Experiments 1, 2, and 3, respectively. Ages ranged between 17 and 26 years. All subjects were right-handed and had normal or corrected-to-normal vision. A false alarm rate of $15 \%$ was set as the criterion for rejecting subjects, and was applied to each background layout (session). For example, for each session of Experiments 1 and 2, there were 28 catch trials among the total 200 trials. Thus, only no more than four false alarms were allowed. This checking 
process resulted in the rejection of one participant in both Experiments 2 and 3.

\section{Stimuli and Procedure}

The stimulus sequence in the present experiments is shown in Figure 7. At the center of the screen was a green fixation cross of $0.4^{\circ} \times 0.4^{\circ}$. Two gray outline rectangles of $8.4^{\circ} \times 1.4^{\circ}\left(0.1^{\circ}\right.$ line width $)$ were horizontally or vertically placed, each of which was $3.5^{\circ}$ away from the fixation (center-to-center). The cue was a gray solid bar of $1.4^{\circ} \times 0.2^{\circ}$, placed at one of the four ends of the two rectangles. The target was a gray filled square of $1.2^{\circ} \times 1.2^{\circ}$, presented at one end of the two rectangles.

Experiments were implemented in a dimly lit and sound-attenuated room. Each block started with a background display containing the fixation cross and two rectangles. This display remained on the screen through each block. After the background display had been presented for several seconds, the cue/target sequence began. First, the cue was presented for $100 \mathrm{msec}$ and then disappeared. After a 200-msec cue-target interval (CTI), the target (or nothing on catch trials) was presented for $150 \mathrm{msec}$. The intertrial interval (ITI) was randomized between 1000 and $1400 \mathrm{msec}$.

All three experiments consisted of two sessions, in which the rectangles were horizontally or vertically placed. For each session, there were four (Experiments 1 and 2) or 20 (Experiment 3) 50-trial blocks. In Experiment 1 , the target appeared at the cued rectangle end on $66 \%$ of total trials (valid), at the other end of the cued rectangle on $10 \%$ of total trials (intra), and at the equidistant end of the other rectangle on $10 \%$ of total trials (inter). Thus, the cue validity (the percentage of valid trials to the total target-present trials) was about $77 \%$. The rest of the trials (14\%) were catch trials. In Experiments 2 and 3, the percentage of the valid, intra, inter, and catch trials was 50\%, 18\%, 18\%, and 14\%, respectively (cue validity, about 58\%).

In all three experiments, participants were told that a target was most likely to appear at the same end as the cue, but it could also appear at other ends, or could be absent. Subjects were instructed to maintain fixation throughout each block and to detect the luminance increment immediately after the cue flash. They were required to press a button when they detected the target and to withhold responses on catch trials. Speed and accuracy were equally emphasized in the instructions. Half of the subjects responded with the right thumb, whereas the other half responded with the left thumb. Before starting each experiment, there were one or several practice blocks to ensure that the subjects could correctly perform the task. The sequence of sessions and blocks was randomized across subjects. In all three experiments, responses were recorded and RTs were calculated. Additionally, in Experiment 3, scalp potentials were recorded while subjects were performing the designated task.

\section{Recording and Analyses}

Repeated measures design was used in all three experiments. Before any statistical analysis, data trimming with the RT window of 150-850 msec was executed to exclude anticipatory and inadvertent responses. For the three experiments, this trimming process resulted in the exclusion of about $0.5 \%, 2.1 \%$, and $1.5 \%$ of targetpresent trials.

RT medians of correct and accepted trials were analyzed with two-way rm-ANOVAs. The GreenhouseGeisser procedure was used to mitigate violations of the sphericity assumption (Jennings \& Wood, 1976; Greenhouse \& Geisser, 1959). The two factors were cue-target relation (valid, intra, and inter) and background layout (horizontal and vertical).

In Experiment 3, the electroencephalogram (EEG) was recorded to hard disk with a NeuroScan acquisition system at a digitizing rate of $250 \mathrm{~Hz}$. Twenty-seven electrodes were placed on the scalp within the framework of the International 10-10 Electrode System (American Electroencephalographic Society, 1994): F7, F3, Fz, F4, F8; FT7, FC3, FC4, FT8; T7, C3, Cz, C4, T8; TP7, CP3, $\mathrm{CPz}, \mathrm{CP} 4$, TP8; P7, P3, Pz, P4, P8; O1, Oz, and O2.

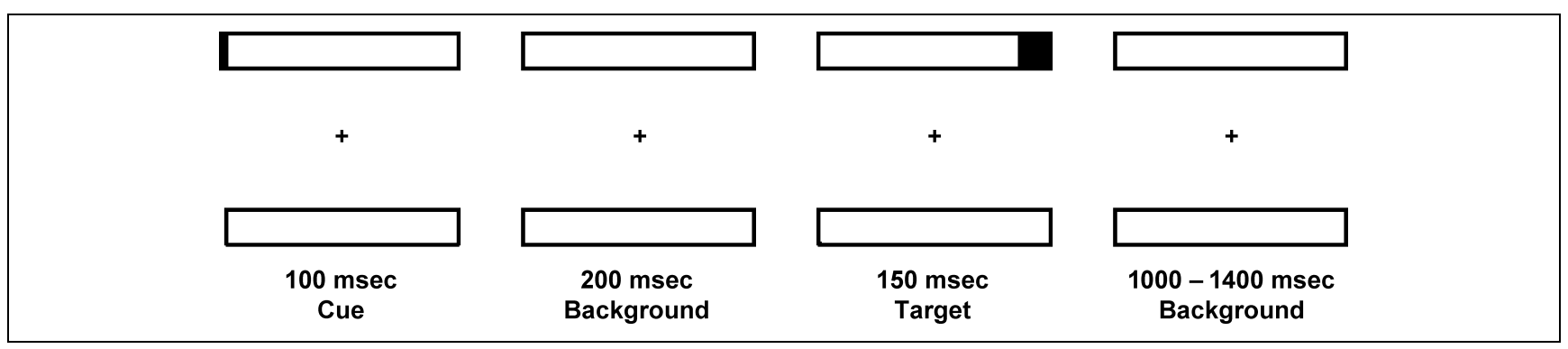

Figure 7. An example of the stimulus sequence in the horizontal session of the present study. A cue could appear at each one of the four ends of background display in a trial. The following target (or no target on catch trials) could appear at the same end as the cue did (valid), at the other end of the same object (intra), or at the equidistant end of the other object (inter). The other session had the same stimuli sequence, except for the different background layout (vertical). The example shown is from the intra condition. 
Electrical activity from the right mastoid (RM) was also recorded. All the above-mentioned electrodes were physically referenced to the left mastoid (LM). Horizontal (from electrodes placed about $5.0 \mathrm{~cm}$ lateral to the left and right outer canthi) and vertical (from electrode placed about $3.0 \mathrm{~cm}$ below the left eye) electrooculogram (EOG) were recorded to measure eye movements. Impedance of each electrode was below $5 \mathrm{k} \Omega$.

EEG data were processed off-line after acquisition. The ERPs were averaged for 1300-msec epochs starting $500 \mathrm{msec}$ before target onset (i.e., $200 \mathrm{msec}$ before cue onset) and ending $800 \mathrm{msec}$ after target onset; the mean voltage of the first 200-msec interval served as baseline. A 0.1 - to $40-\mathrm{Hz}$ band-pass filtering and an artifact rejection with criterion of $\pm 60 \mu \mathrm{V}$ were applied. The algebraically determined mean voltage of left and right mastoids was used as reference. Trials with incorrect responses were excluded from any RT or ERP analysis.

ERP averaging generated three waveforms (valid, intra, and inter) for each individual. The neural responses to the cue overlapped with the responses to the target stimulus because of the use of short CTOA. However, because a constant CTOA was used, the adjacent response (Adjar) filter method (Woldorff, 1993) could not be used to remove the distortion from overlapping potentials. To eliminate the possibility that any differences in early target ERP components might be due to overlapping and distortion from cue ERPs, the ERP waveforms of each subject were produced by taking the same number of trials from each location, each session, and each cue-target relation into the averaging procedure. Therefore, the ERP distortion cannot account for the differences between compared conditions (for detailed analysis and description, see Appendix). After the averaging process, the main deflections of the ERP waveforms were measured with mean amplitude calculations (see Table 2) and subjected to rm-ANOVAs (Greenhouse-Geisser module). The two factors were cue-target relation (valid, intra, and inter) and hemisphere (left and right; just for lateral sites).

\section{APPENDIX}

When visual stimuli are presented at a fast rate, the ERPs of temporally adjacent stimuli overlap. The distortion due to overlap can be diminished through "jitter," and further corrected with the Adjar technique (Woldorff, 1993). The Adjar technique subtracts out overlapping scalp potential changes that are time-locked to the previous stimulus, leaving those that are time-locked to the current stimulus (Woldorff, 1993, p. 112). However, when an experiment uses a constant CTOA, the ERP time-locked to the previous stimulus is also time-locked to the current stimulus, which makes the Adjar technique inapplicable (see Woldorff, 1993, pp. 109-115).

The ERP distortion does not necessarily bring artifacts into the results of the differences between compared conditions. For example, superimposing the same segment of ERP on two ERP waveforms does not change the difference between them. Artifacts come from the differential overlap between electrophysiological responses to temporal adjacent stimuli. In the field of visual attention research, two types of imbalance of the previous stimuli, namely, the physical property imbalance and attentional state imbalance, may introduce artifacts (differential overlap) to the results of statistical comparisons. Figure 8A shows an example of trial-bytrial attention orienting to the left/right visual fields with a peripheral cue. The designated comparison is between the validly cued and the invalidly cued conditions. Because each possible location is expected to have the same probability of cue onset, there is no difference of attentional state (or expectancy) between cues at different locations. For stimuli in the left visual field, the valid target was always preceded by a left cue, whereas the invalid target was always preceded by a right cue. Therefore, the difference between the ERPs with the left cue and right cue (different physical property: location) will bring artifacts into the observed difference between the two conditions. In a sustained attention paradigm (Figure 8B), a left stimulus was equally likely to be preceded by left stimuli as by right stimuli.

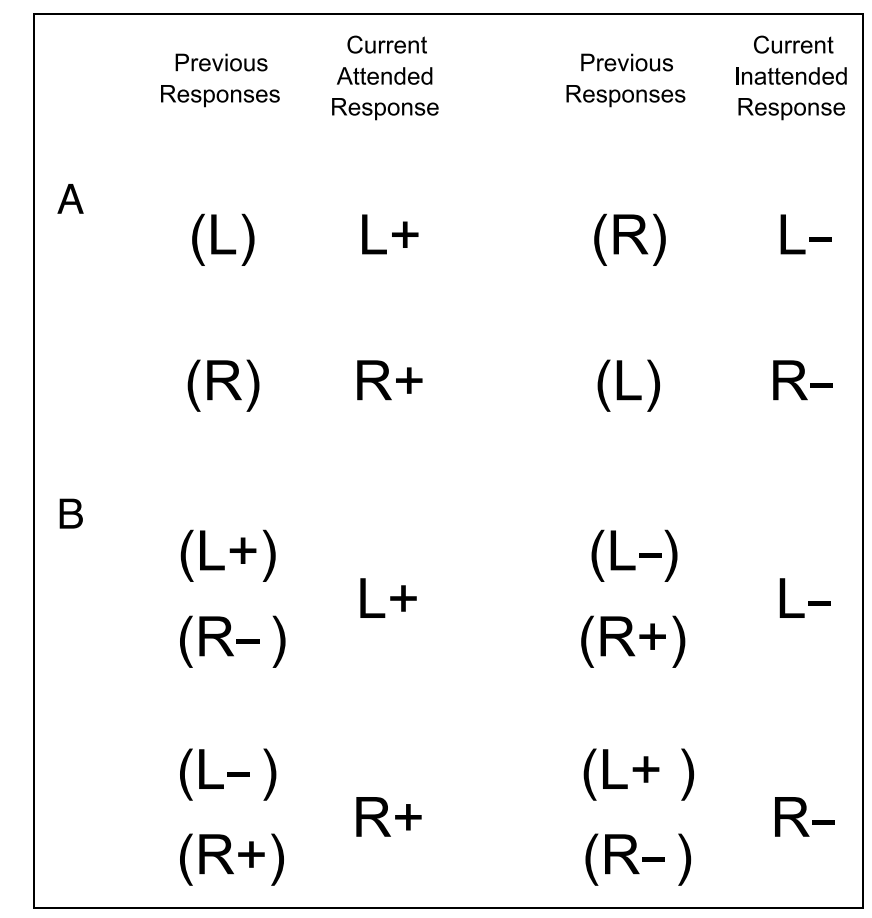

Figure 8. Imbalance in visual attention research. Stimuli are presented in the left visual field $(\mathrm{L})$ or in the right visual field $(\mathrm{R})$. (A) Physical property imbalance in a trial-by-trial orienting study with peripheral cue. Cue (previous) stimuli have no difference of attentional state. (B) Attentional state imbalance in a sustained attention experiment. The current stimulus is equally likely to be preceded by left stimuli or by right stimuli (adapted from Woldorff, 1993). A plus sign $(+)$ indicates the attended response, whereas a minus sign $(-)$ indicates the inattended response. 
Although the physical properties of the previous stimuli were balanced, in this case their corresponding attentional states did not match. Taken that attention modulates neural responses to visual stimuli, the overlap on the current attended response $(\mathrm{L}+)$ from previous responses of left stimuli ( $\mathrm{L}+$ 's) will not be the same as the overlap on the current inattended response $(\mathrm{L}-$ ) from previous responses of left stimuli (L-'s). Similarly, the overlaps from previous responses of right stimuli (R+'s vs. R-'s) are also different. Thus, the current attended and inattended ERPs of left stimuli are overlapped by different preceding waveforms (see Woldorff, 1993 , p. 104). By the same reasoning, the current attended and inattended ERPs of right stimuli are also differently overlapped by the responses of previous stimuli. The above-described situation is true in both the trialby-trial orienting and sustained attention paradigms.

One possible solution to the differential overlap problem when the Adjar technique is disabled is to directly subtract the ERPs without the presence of the current stimulus from the ERPs with the presence of the current stimulus. However, because physiological processes are usually not additive (see, e.g., Picton et al., 2000, p. 140), this solution is not widely suggested with the exception of few certain situations, say, in the post probe paradigm (e.g., Luck et al., 1993). Another solution is to precisely balance the physical properties and the attentional states, as we have done in the present study. This method is described in detail below.

In the present ERP experiment, each target was preceded by a peripheral cue, which covertly oriented the visual attention. Because the ITI was long and well

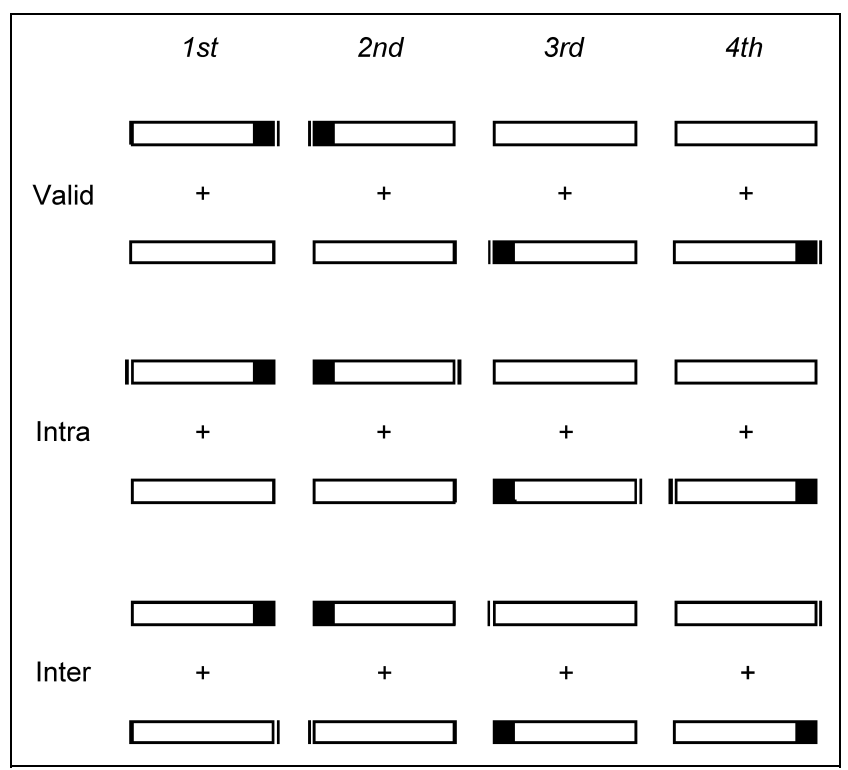

Figure 9. Physical property balance in the present ERP experiment. Each row represents a cue-target relation type. Each column shows the trial types with target presented in the same quadrant of visual field. Only stimuli of the horizontal session are plotted.

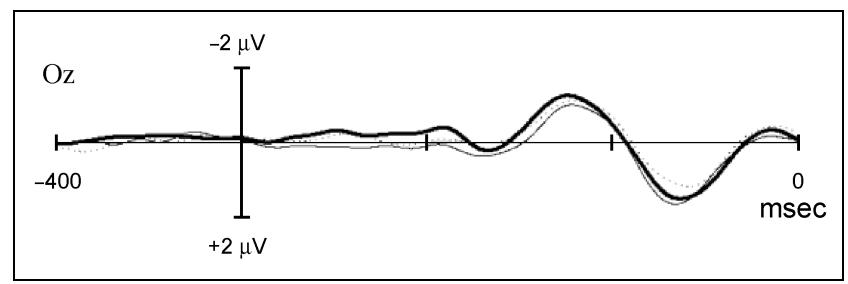

Figure 10. An example of cue-elicited ERP waveforms after balancing the physical properties (site Oz). The waveforms are shown from $100 \mathrm{msec}$ before cue onset to $300 \mathrm{msec}$ after cue onset (i.e., the time point of target onset). No evident difference between conditions is observed. Note that the target onset is at $0 \mathrm{msec}$, and the cue onset is at $-300 \mathrm{msec}$.

jittered (1000-1400 msec), the current stimulus (target) was not subject to the distortion of the previous trial but only to the distortion of the previous stimulus (cue of the same trial). As noted earlier, balancing the attentional states is unnecessary because there is no expectancy difference between cues at different locations in the trial-by-trial orienting paradigm. Figure 9 demonstrates the balancing of the physical properties. Without the balancing, the current stimulus received differential overlap from the peripheral cue (each column of Figure 9). Considering the cue and target as a combined stimulus, we can see that after taking the same number of trials from each location and each cue-target relation into the averaging procedure, the physical properties of the cuetarget stimuli are identical under different conditions. The only difference between the three conditions (each row of Figure 9 represents a condition) is the cue-target relation (or, the processing interaction of the cue and target; see Woldorff, 1993, p. 112), which is our research interest.

Although the cue ERPs still overlap and distort the target ERPs, this distortion is identical under the three to-be-compared conditions. Therefore, any difference between these conditions cannot be accounted for by the distortion from the cue ERPs. Figure 10 is an example of the cue ERPs of the present ERP experiment, showing no evident difference between conditions during the first 300 msec after cue onset. However, because the factor of stimulus location is collapsed after the balancing procedure, the analyses of visual fields and contralateral/ipsilateral ERPs are disabled.

\section{Acknowledgments}

This research was supported by the National Natural Science Foundation of China (Grant No. 697900800), the Ministry of Science and Technology of China (Grant No. 1998030503), and the Chinese Academy of Sciences (Grant Nos. KGCX2-SW-101 and KJCX1-07). The authors are grateful to Shihui Han for his comments on this article. We thank Todd C. Handy, Steven A. Hillyard, and one anonymous reviewer for helpful comments and suggestions on a previous version of the manuscript. Special thanks are owed to Steve Hillyard for his kindness in correcting our English. 
Reprint requests should be sent to Lin Chen, Key Laboratory of Cognitive Science, Institute of Biophysics, Chinese Academy of Sciences, 15 Datun Road, Beijing, 100101, PR China, or via e-mail:cl@cogsci.ibp.ac.cn.

\section{REFERENCES}

American Electroencephalographic Society. (1994). Guidelines for standard electrode position nomenclature. Journal of Clinical Neurophysiology, 11, 111-113.

Berger, A., Dori, H., \& Henik, A. (1999). Peripheral non-informative cues do induce early facilitation of target detection. European Journal of Cognitive Psychology, 11, 119-137.

Blaser, E., Pylyshyn, Z. W., \& Holcombe, A. O. (2000). Tracking an object through feature space. Nature, 408 , 196-199.

Cave, K. R., \& Bichot, N. P. (1999). Visuospatial attention: Beyond a spotlight model. Psychonomic Bulletin and Review, 6, 204-223.

Clark, V. P., Fan, S., \& Hillyard, S. A. (1995). Identification of early visual evoked potential generators by retinotopic and topographic analyses. Human Brain Mapping, 2, 170-187.

Clark, V. P., \& Hillyard, S. A. (1996). Spatial selective attention affects early extrastriate but not striate components of the visual evoked potential. Journal of Cognitive Neuroscience, 8, 387-402.

Di Russo, F., Martínez, A., Sereno, M. I., Pitzalis, S., \& Hillyard, S. A. (2001). Cortical sources of the early components of the visual evoked potential. Human Brain Mapping, 15, 95-111.

Downing, C. J., \& Pinker, S. (1985). The spatial structure of visual attention. In M. I. Posner \& O. S. M. Marin (Eds.), Attention and performance XI (pp. 171-187). Hillsdale, NJ: Erlbaum.

Duncan, J. (1984). Selective attention and the organization of visual information. Journal of Experimental Psychology: General, 113, 501-517.

Eason, R. G. (1981). Visual evoked potential correlates of early neural filtering during selective attention. Bulletin of the Psychonomic Society, 18, 203-206.

Egly, R., Driver, J., \& Rafal, R. D. (1994). Shifting visual attention between objects and locations: Evidence from normal and parietal lesion subjects. Journal of Experimental Psychology: General, 123, 161-177.

Eimer, M. (1998). Mechanisms of visuospatial attention: Evidence from event-related brain potentials. Visual Cognition, 5, 257-286.

Eimer, M. (1993). Spatial cueing, sensory gating and selective response preparation: An ERP study on visuo-spatial orienting. Electroencephalography and Clinical Neurophysiology, 88, 408-420.

Eriksen, C. W., \& Yeh, Y. (1985). Allocation of attention in the visual field. Journal of Experimental Psychology: Human Perception and Performance, 11, 583-597.

Gomez Gonzalez, C. M., Clark, V. P., Fan, S., Luck, S. J., \& Hillyard, S. A. (1994). Sources of attention-sensitive visual event-related potentials. Brain Topography, 7, 41-51.

Greenhouse, W. W., \& Geisser, S. (1959). On methods in the analysis of profile data. Psychometrika, 24, 95-112.

Heinze, H. J., Luck, S. J., Mangun, G. R., \& Hillyard, S. A. (1990). Visual event-related potentials index focused attention within bilateral stimulus arrays. I. Evidence for early selection. Electroencephalography and Clinical Neurophysiology, 75, 511-527.

Heinze, H. J., Mangun, G. R., Burchert, W., Hinrichs, H., Scholz, M., Münte, T. F., Gös, A., Scherg, M., Johannes, S.,
Hundeshagen, H., Gazzaniga, M. S., \& Hillyard, S. A. (1994). Combined spatial and temporal imaging of brain activity during selective attention in humans. Nature, 372, 543-546.

Hopfinger, J. B., \& Mangun, G. R. (2001). Tracking the influence of reflexive attention on sensory and cognitive processing. Cognitive, Affective, and Behavioral Neuroscience, 1, 56-65.

Hopfinger, J. B., \& Mangun, G. R. (1998). Reflexive attention modulates processing of visual stimuli in human extrastriate cortex. Psychological Science, 9, 441-447.

Jennings, J. R., \& Wood, C. C. (1976). The $\epsilon$-adjustment procedure for repeated measures analyses of variance. Psychophysiology, 13, 277-278.

Jonides, J. (1981). Voluntary versus automatic control over the mind's eye. In J. Long \& A. Baddeley (Eds.), Attention and performance IX (pp. 187-203). Hillsdale: Erlbaum.

Kahneman, D., \& Henik, A. (1981). Perceptual organization and attention. In M. Kubovy \& J. Pomerantz (Eds.), Perceptual organization (pp. 181-211). Hillsdale: Erlbaum.

Koffka, K. (1923). Perception: An introduction to the Gestalt-theorie. Psychological Bulletin, 19, 531-585.

Luck, S. J. (1998). Neurophysiology of selective attention. In H. Pashler (Ed.), Attention (pp. 257-295). Hove: Psychology Press.

Luck, S. J., Fan, S., \& Hillyard, S. A. (1993). Attention-related modulation of sensory-evoked brain activity in a visual search task. Journal of Cognitive Neuroscience, 5 , 188-195.

Luck, S. J., \& Hillyard, S. A. (2000). The operation of selective attention at multiple stages of processing: Evidence from human and monkey electrophysiology. In M. S. Gazzaniga (Ed.), The new cognitive neurosciences (2nd ed., pp. 687-700). Cambridge: MIT Press.

Mangun, G. R. (1995). Neural mechanisms of visual selective attention. Psychophysiology, 32, 4-18.

Mangun, G. R., \& Hillyard, S. A. (1991). Modulations of sensory-evoked potentials indicate changes in perceptual processing during visual-spatial priming. Journal of Experimental Psychology: Human Perception and Performance, 17, 1057-1074.

Mangun, G. R., \& Hillyard, S. A. (1990). Allocation of visual attention to spatial locations: Tradeoff functions for event-related potentials and detection performance. Perception and Psychophysics, 47, 532-550.

Mangun, G. R., Jha, A. P., Hopfinger, J. B., \& Handy, T. C. (2000). The temporal dynamics and functional architecture of attentional processes in human extrastriate cortex. In M. S. Gazzaniga (Ed.), The new cognitive neurosciences (2nd ed., pp. 701-710). Cambridge: MIT Press.

Martínez, A., Di Russo, F., Anllo-Vento, L., Sereno, M. I., Buxton, R. B., \& Hillyard, S. A. (2001). Putting spatial attention on the map: Timing and localization of stimulus selection processes in striate and extrastriate visual areas. Vision Research, 41, 1437-1457.

Müller, H. J., \& Findlay, J. M. (1988). The effect of visual attention on peripheral discrimination thresholds in single and multiple element displays. Acta Psychologica, 69, 129-155.

Müller, H. J., \& Rabbitt, P. M. A. (1989). Reflexive and voluntary orienting of visual attention: Time course of activation and resistance to interruption. Journal of Experimental Psychology: Human Perception and Performance, 15, 315-330.

O'Craven, K., Downing, P., \& Kanwisher, N. (1999). fMRI evidence for objects as the units of attentional selection. Nature, 401, 584-587. 
Palmer, S. E. (1999). Organizing objects and scenes. In S. E. Palmer (Ed.), Vision science: Photons to phenomenology (pp. 254-310). Cambridge: MIT Press.

Pashler, H., Johnston, J. C., \& Ruthruff, E. (2001). Attention and performance. Annual Review of Psychology, 52, 629-651.

Picton, T. W., Bentin, S., Berg, P., Donchin, E., Hillyard, S. A., Johnson, R., Jr., Miller, G. A., Ritter, W., Ruchkin, D. S., Rugg, M. D., \& Taylor, M. J. (2000). Guidelines for using human event-related potentials to study cognition: Recording standards and publication criteria. Psychophysiology, 37, 127-152.

Posner, M. I. (1980). Orienting of attention. Quarterly Journal of Experimental Psychology, 32, 3-25.

Rugg, M. D., \& Coles, M. G. H. (1995). The ERP and cognitive psychology: Conceptual issues. In M. D. Rugg \& M. G. H. Coles (Eds.), Electrophysiology of mind: Event-related brain potentials and cognition (pp. 27-39). Oxford: Oxford University Press.

Scholl, B. J. (2001). Objects and attention: The state of the art. Cognition, 80, 1-46.
Shiffrin, R. M., \& Schneider, W. (1977). Controlled and automatic human information processing: II. Perceptual learning, automatic attending, and a general theory. Psychological Review, 84, 127-190.

Valdes-Sosa, M., Bobes, M. A., Rodriguez, V., \& Pinilla, T. (1998). Switching attention without shifting the spotlight: Object-based attentional modulation of brain potentials. Journal of Cognitive Neuroscience, 10, 137-151.

Wertheimer, M. (1938). Laws of organization in perceptual forms. In W. Ellis (Ed.), A source book of gestalt psychology (pp. 71-88). London: Routledge \& Kegan Paul.

Woldorff, M. G. (1993). Distortion of ERP averages due to overlap from temporally adjacent ERPs: Analysis and correction. Psychophysiology, 30, 98-119.

Yantis, S. (1998). Control of visual attention. In H. Pashler (Ed.), Attention (pp. 223-256). Hove: Psychology Press.

Yantis, S., \& Jonides, J. (1990). Abrupt visual onsets and selective attention: Voluntary versus automatic allocation. Journal of Experimental Psychology: Human Perception and Performance, 16, 121-134. 
Copyright of Journal of Cognitive Neuroscience is the property of MIT Press and its content may not be copied or emailed to multiple sites or posted to a listserv without the copyright holder's express written permission. However, users may print, download, or email articles for individual use. 
Copyright of Journal of Cognitive Neuroscience is the property of MIT Press and its content may not be copied or emailed to multiple sites or posted to a listserv without the copyright holder's express written permission. However, users may print, download, or email articles for individual use. 